\title{
Development of colorless wood via two-step delignification involving alcoholysis and bleaching with maintaining natural hierarchical structure
}

\author{
Yoshiki Horikawa $^{1 *} \mathbb{C}$, Rino Tsushima ${ }^{1}$, Keiichi Noguchi ${ }^{2}$, Satoshi Nakaba ${ }^{1}$ and Ryo Funada ${ }^{1}$
}

\begin{abstract}
Lignin-free wood has been successfully developed via a two-step chemical treatment while maintaining its inherent hierarchical structure. The first step was alcoholysis which was conducted using ethylene glycol, and whose condition was optimized by monitoring the removal of lignin using infrared spectroscopy. The second step was bleaching wherein the delignification proceeded from the surface to the core of the wood block, and finally resulted in complete decolorization. Although the wood block was free from lignin and hemicellulose as approximately confirmed by the chemical composition analysis, the 3-dimensional colorless wood block was almost unaltered, even after freeze-drying. Then, multidirectional observation was performed to investigate whether the natural hierarchical structure from anatomical- to nano-level was maintained. Optical microscopy, X-ray microcomputed tomography, X-ray diffractometry, and transmission electron microscopy demonstrated that all the stages of hierarchical structure were maintained. The lignin-free wood block has great potential for novel materials that are supported by a 3-dimensional wooden architecture. The derived lignin-free wood is also a suitable specimen that can be used to understand the formation and functionality of the anatomical structure and lignified cell wall.
\end{abstract}

Keywords: Delignification, Cellulose, Microfibril, Hemicellulose

\section{Introduction}

Trees produce organic compounds through photosynthesis and accumulate them in the body. An example is wood, which consists of different cell types that aid in mechanical support, water transportation, storage of nutrient sources and the synthesis of physiological active substances. The cell wall of wood is based on multi-layers that are constructed from the oriented cellulose microfibrils, which directly interact with hemicellulose and indirectly with lignin. The highly controlled hierarchical structure signifies the remarkable mechanical properties, which facilitate the support of the huge bodies

\footnotetext{
*Correspondence: horikaw@cc.tuat.ac.jp

${ }^{1}$ Institute of Agriculture, Tokyo University of Agriculture and Technology, Fuchu, Tokyo 183-8509, Japan

Full list of author information is available at the end of the article
}

of tress and their millenary existence. Wood has been used extensively to produce a variety of products along the natural hierarchical structure, such as timber, pulp and microfibril, which have recently been referred to as "nanofiber".

The preparation method used for the fabrication of nanofibers has been established via three approaches, namely mechanical processing using a grinder [1], aqueous counter collision [2] and a combination of chemical and mechanical treatments using 2,2,6,6-tetramethylpiperidine-1-oxyl free radical (TEMPO)-mediated oxidation [3]. The special chemical used in the latter approach allows the regioselective conversion of C6 primary hydroxyls to carboxylate groups [4]. For the cellulose microfibril, only the molecules localized on the surface of the crystal were oxidized, which resulted in the formation
Springer Open (c) The Author(s) 2020. This article is licensed under a Creative Commons Attribution 4.0 International License, which permits use, sharing, adaptation, distribution and reproduction in any medium or format, as long as you give appropriate credit to the original author(s) and the source, provide a link to the Creative Commons licence, and indicate if changes were made. The images or other third party material in this article are included in the article's Creative Commons licence, unless indicated otherwise in a credit line to the material. If material is not included in the article's Creative Commons licence and your intended use is not permitted by statutory regulation or exceeds the permitted use, you will need to obtain permission directly from the copyright holder. To view a copy of this licence, visit http://creativeco mmons.org/licenses/by/4.0/. 
of individualized nanofibers under the influence of mechanical treatment [5]. Although nanofibers comprise low densities of $1.6 \mathrm{~g} / \mathrm{cm}^{3}$, the tensile strengths and Young's moduli of single microfibrils are approximately $3 \mathrm{GPa}$ and $140 \mathrm{GPa}$, respectively [6, 7]. Based on cellulose nanofiber, mixture with a matrix component such as latex results in high mechanical strength [8]. Using microfibrillated cellulose without chemical surface modification, reinforced material using polylactic acid and polypropylene was successfully prepared $[9,10]$. If cellulose nanofibers are aligned, more high-strength materials are developed. However, once the cellulose microfibrils from terrestrial plants are individually dispersed in water, it becomes extremely difficult to reorient. Therefore, removal of the hemicellulose and lignin makes the development of a cellulose material that comprises the natural wood architecture achievable.

To develop a novel material that is based on cellulose microfibrils and supported by the wood hierarchical structure, researchers have examined the removal of the matrix components. Yano et al. reported partial removal of lignin by $\mathrm{NaClO}_{2}$ followed by $\mathrm{NaOH}$ treatment, and the high-strength wood was subsequently developed by impregnating the resin [10]. Optically transparent wood was also successfully obtained by delignification using $\mathrm{NaClO}_{2}$, which was followed by the impregnation of prepolymerized methyl methacrylate [11]. A combination of delignification through boiling in an aqueous mixture of $\mathrm{NaOH}$ and $\mathrm{Na}_{2} \mathrm{SO}_{3}$, with hot-pressing was achieved in the development of densified wood with outstanding strength [12]. However, the complete removal of lignin is difficult and not achievable by exclusive aqueous processing.

To create cellulose material that can be a novel filler for polymer composite, the present study initially determines the chemical treatment required to prepare ligninfree wood, while maintaining the original morphology. Delignification using alcohols, such as ethanol, ethylene glycol, and glycerol, has been reported to effectively remove the lignin from the biomass [13-15]. From the list of alcohols previously mentioned, ethanol is a solvent with a low-boiling point. The relatively higher pressure when a reaction occurs at high temperature poses a danger. Glycerol is a solvent with a high-boiling point, but is a high-viscosity liquid that is difficult to handle during chemical processing. On the other hand, ethylene glycol is a solvent with a high boiling point and whose low viscosity. The alcoholysis using ethylene glycol was therefore optimized to the reaction temperature and $\mathrm{H}_{2} \mathrm{SO}_{4}$ was added to increase the acid content and thus facilitate the efficient removal of the lignin. Acid was added as a catalyst because, in its absence, the reaction is significantly less effective during the alcoholysis of wood [16]. In the second stage, the reaction times for the bleaching process were determined based on the decolorization of the wood samples and chemical analysis. To verify the preservation of the hierarchical structure of the wood, multiple structural assessments were conducted. X-ray microcomputed tomography $(\mu \mathrm{CT})$, X-ray diffraction (XRD) analysis, and transmission electron microscopy (TEM) observation combined with TEMPO-mediated oxidation revealed the preservation of the woody structure from the anatomical- to nano-architecture.

\section{Materials and methods}

\section{Sample preparation}

Wood block of $10 \mathrm{~mm}$ (longitudinal) $\times 10 \mathrm{~mm}$ (radial) $\times 10 \mathrm{~mm}$ (tangential) dimensions obtained from Cryptomeria japonica was used throughout this study. For the alcoholysis, the block was immersed in the solvent and annealed using a portable reactor (TVS-N2 Type, Taiatsu Techno Corp, Japan). The solvent was examined by changing the ratios of ethylene glycol, water, and $97 \% \mathrm{H}_{2} \mathrm{SO}_{4}$ (Wako, Japan) at different temperatures, as shown in Table 1 . All reactions for the alcoholysis process were performed in $1 \mathrm{~h}$. The products obtained were washed with distilled water. The bleaching process was performed according to the Wise method [17], whereby lignin was removed by a sodium chlorite solution at $70^{\circ} \mathrm{C}$. The products that were obtained were washed with distilled water.

\section{IR spectroscopy}

Fourier transform infrared (IR) spectroscopy employing a PerkinElmer Frontier system (Waltham, MA, USA) with an Attenuated Total Reflection (ATR) accessory was used to obtain IR spectra. Dried powder samples or radial sections were removed from the block of wood using a blade placed on a reflection diamond in the ATR crystal in a top plate assembly. The spectra were acquired in the $4000-500 \mathrm{~cm}^{-1}$ range with a resolution of $4 \mathrm{~cm}^{-1}$ and an acquisition of eight scans. The spectral pretreatments were carried out using ATR correction functions equipped with PerkinElmer spectroscopic software packages, which was followed by normalization based on the top band of the fingerprint region at $\sim 1000 \mathrm{~cm}^{-1}$.

\section{Analysis of chemical components}

The monosaccharides and lignin contents were estimated according to the published report [18]. The wood samples were subjected to acid hydrolysis in a twostage treatment with sulfuric acid. The initial hydrolysis involved treatment with $72 \%$ sulfuric acid at $30{ }^{\circ} \mathrm{C}$ for $1 \mathrm{~h}$. In contrast, the second processing was performed with $4 \%$ sulfuric acid at $121{ }^{\circ} \mathrm{C}$ for $1 \mathrm{~h}$, wherein the monosaccharides were separated in the liquor fraction from the 
Table 1 Alcoholysis condition and lignin content predicted from IR spectra

\begin{tabular}{|c|c|c|c|c|c|}
\hline Sample no. & Ethylene glycol & $\mathrm{H}_{2} \mathrm{O}$ & $97 \% \mathrm{H}_{2} \mathrm{SO}_{4}$ & Temperature $\left({ }^{\circ} \mathrm{C}\right)$ & $\begin{array}{l}\text { Lignin content } \\
\text { predicted by IR } \\
\text { spectra (\%) }\end{array}$ \\
\hline 0 & - & - & - & - & $35.9 \pm 1.99$ \\
\hline 1 & 0 & 100 & 0 & 180 & $35.7 \pm 3.63$ \\
\hline 2 & 90 & 5 & 5 & 150 & $33.8 \pm 1.36$ \\
\hline 3 & 95 & 2.5 & 2.5 & 140 & $22.6 \pm 2.29$ \\
\hline 4 & 95 & 2.5 & 2.5 & 150 & $19.3 \pm 1.54$ \\
\hline 5 & 95 & 2.5 & 2.5 & 160 & $26.7 \pm 2.86$ \\
\hline 6 & 95 & 2.5 & 2.5 & 170 & $49.6 \pm 4.51$ \\
\hline 7 & 95 & 2.5 & 2.5 & 180 & $24.3 \pm 3.51$ \\
\hline 8 & 95 & 0 & 5 & 180 & $46.6 \pm 1.65$ \\
\hline 9 & 96 & 0 & 4 & 180 & $45.2 \pm 2.01$ \\
\hline 10 & 98 & 1 & 1 & 150 & $22.1 \pm 5.47$ \\
\hline 11 & 99 & 0.5 & 0.5 & 110 & $35.5 \pm 2.69$ \\
\hline 12 & 99 & 0.5 & 0.5 & 120 & $27.0 \pm 2.90$ \\
\hline 13 & 99 & 0.5 & 0.5 & 130 & $22.8 \pm 2.21$ \\
\hline 14 & 99 & 0.5 & 0.5 & 140 & $18.0 \pm 3.43$ \\
\hline 15 & 99 & 0.5 & 0.5 & 150 & $16.2 \pm 5.93$ \\
\hline 16 & 99 & 0.5 & 0.5 & 160 & $16.4 \pm 3.26$ \\
\hline 17 & 99 & 0.5 & 0.5 & 170 & $16.4 \pm 4.46$ \\
\hline 18 & 99 & 0.5 & 0.5 & 180 & $16.3 \pm 4.06$ \\
\hline 19 & 99 & 1 & 0 & 150 & $32.6 \pm 1.19$ \\
\hline 20 & 100 & 0 & 0 & 150 & $26.8 \pm 1.91$ \\
\hline 21 & 100 & 0 & 0 & 180 & $45.8 \pm 1.88$ \\
\hline
\end{tabular}

The values on ethylene glycol, $\mathrm{H}_{2} \mathrm{O}$ and $97 \% \mathrm{H}_{2} \mathrm{SO}_{4}$ indicate a weight ratio in reaction solvent

The value on lignin content shows the average and standard deviation calculated from 3 samples

solid components. The solid residue was weighed as the lignin content because the ash content in the wood of Cryptomeria japonica had previously been reported as negligible [19]. However, the acid-soluble lignin was not quantifiable, although traces were present in the liquor fraction after the two-stage acid hydrolysis. The monosaccharides in the liquor fraction were estimated using a high-performance liquid chromatography (HPLC) system equipped with an Asahipak NH2P-50 4E column, an RF-AXL fluorescence detector, an autosampler, and a pneumatic controller (Prominence UFLC; Shimadzu Corp., Kyoto, Japan). Polysaccharide content was calculated from the concentration of the corresponding monosaccharide, using anhydrous correction factors of 0.90 for glucose, mannose and galactose, and a correction of 0.88 for xylose and arabinose.

\section{Optical microscopic observation}

The specimens were gradually dehydrated with an ethanol series and subjected to propylene oxide as a substituting agent. The samples were then embedded in epoxy resin, and thin sections of approximately $1 \mu \mathrm{m}$ thickness were obtained using a rotary microtome (Microm HM
340 E, Thermo Scientific, MA, USA). Periodic acidSchiff (PAS) staining was carried out using a commercial kit (Cosmo Bio Co., Ltd., Japan). The section was oxidized in a periodic acid solution for $5 \mathrm{~min}$. After washing with water, the section was incubated in Schiff's reagent for $15 \mathrm{~min}$ and $3 \mathrm{~h}$ for the untreated wood block and the colorless wood block, respectively. After washing in a sulfurous acid solution and then in distilled water, the stained sections were observed by the optical microscopy (BX61, Olympus, Tokyo, Japan).

\section{X-ray $\mu \mathrm{CT}$}

Untreated and colorless woods were scanned using an X-ray $\mu C T$ system (InspeXio SMX-90CT Plus, Shimazu, Kyoto, Japan). The scanning resolution was set to $0.004 \mathrm{~mm} /$ voxel and the machine conditions were set to $60 \mathrm{kV}$ and $40 \mu \mathrm{A}$.

\section{X-ray diffraction analysis}

The radial sections were rolled along the axis in the L-direction to average the earlywood and latewood structural information. The X-ray fiber diffraction patterns were recorded by the R-AXIS RAPID system (Rigaku, 
Tokyo, Japan), which was equipped with an imaging plate using the graphite-monochromatized $\mathrm{Cu}-\mathrm{K} \alpha$ radiation $(\lambda=0.15,418 \mathrm{~nm})$ from an $\mathrm{X}$-ray generator operated at $50 \mathrm{kV}$ and $250 \mathrm{~mA}$. The camera length between the sample and the imaging plate was $127.4 \mathrm{~mm}$.

$\mathrm{X}$-ray diffractograms were collected in reflection mode with $\mathrm{Cu}-\mathrm{K} \alpha$ radiation $(\lambda=0.15418 \mathrm{~nm})$, which was generated from an UltraX-18HF diffractometer (Rigaku, Tokyo, Japan) operated at $40 \mathrm{kV}$ and $300 \mathrm{~mA}$.

\section{TEMPO-mediated oxidation}

The colorless wood block was oxidized by the TEMPO/ $\mathrm{NaBr} / \mathrm{NaClO}$ system by dosing with $10 \mathrm{mmol} / \mathrm{g} \mathrm{NaClO}$ in water at $\mathrm{pH} 10$ under room temperature conditions. To reduce the C6-aldehydes and $\mathrm{C} 2 / \mathrm{C} 3$ ketones to alcohols that were partially produced during TEMPO-oxidization, the sample that was obtained was subjected to $\mathrm{NaBH}_{4}$ in water at the $\mathrm{pH}$ of 10 for $3 \mathrm{~h}$; this was aimed at reducing these functional groups to hydroxyl groups [20]. The product was repeatedly washed in distilled water on a nylon filter and then disintegrated in water for $1 \mathrm{~min}$ by employing a double-cylinder-type homogenizer (Hiscotron; Microtec, Chiba, Japan).

\section{TEM observation}

The suspension liquid with cellulose microfibrils was applied to a copper grid with carbon film support (Okenshoji, Tokyo, Japan). After negative staining with $2 \%$ uranyl acetate, TEM observation was performed by a JEM-1400 Plus TEM (JEOL, Tokyo, Japan) at $80 \mathrm{kV}$.

\section{Results and discussion}

The wood was sequentially subjected to two steps: alcoholysis and bleaching, to facilitate the removal of lignin and hemicellulose with maintaining wood morphology and its natural architecture (Fig. 1a, b).

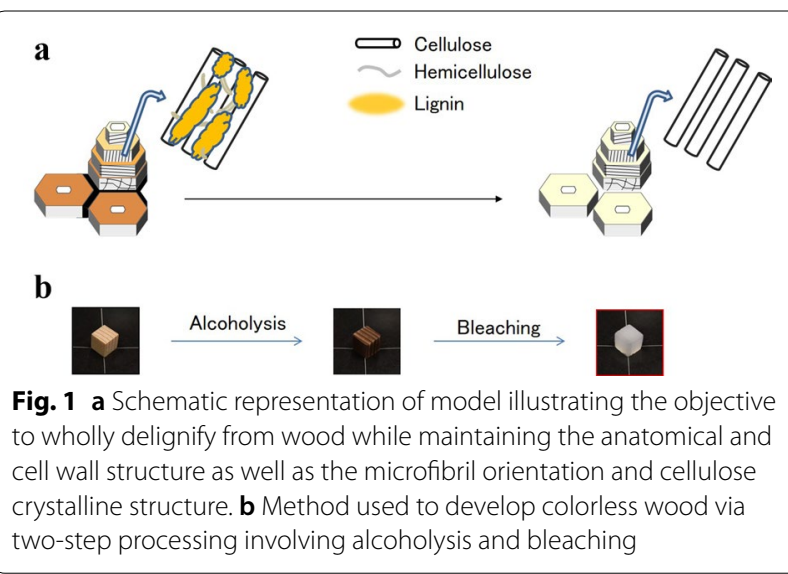

\section{Optimization of alcoholysis}

To optimize the alcoholysis, various conditions that involve changing the ratio of ethylene glycol and $97 \%$ $\mathrm{H}_{2} \mathrm{SO}_{4}$, were examined as shown in Table 1. The alcoholysis samples were evaluated by IR spectroscopy and their lignin contents were estimated from IR spectra using a reported calibration model [21]. Figure 2 shows representative IR spectra before and after alcoholysis with changes in the solvent. Although a wood block was treated in the liquid mixture of ethylene glycol and water at $150{ }^{\circ} \mathrm{C}$, the resulting spectrum was almost unaltered, when compared to that of the untreated sample (Fig. 2a, b). In contrast, when the wood was subjected to ethylene glycol containing acid at the same temperature, the lignin was effectively removed as the intensity of the band at $1508 \mathrm{~cm}^{-1}$ that was ascribed to the aromatic skeletal vibration (Fig. 2c). However, a higher concentration of acid in the reaction liquid at higher temperatures resulted in carbonization, which resulted in a destructive change in the fingerprint region at the $1200-800 \mathrm{~cm}^{-1}$ range (Fig. 2d). In addition, IR absorbance around $3400 \mathrm{~cm}^{-1}$ assigned to the $\mathrm{OH}$ stretching vibration became broader and shifted to a higher wavenumber. This indicated that the crystalline structure of cellulose was decomposed during the harsh alcoholysis. Therefore, it was essential to determine a suitable solvent and reaction temperature. From the chemically treated samples presented in Table 1, the solvent mixture in a ratio of 99:0.5:0.5 corresponding to ethylene glycol:water:97\% $\mathrm{H}_{2} \mathrm{SO}_{4}$ could effectively remove the lignin. To determine the optimum reaction temperature, the lignin content of wood samples after alcoholysis in the corresponding solvent was monitored at an elevated temperature. Figure 3 shows that lignin content decreased at higher temperatures until $150{ }^{\circ} \mathrm{C}$; however, it remained unchanged at temperatures

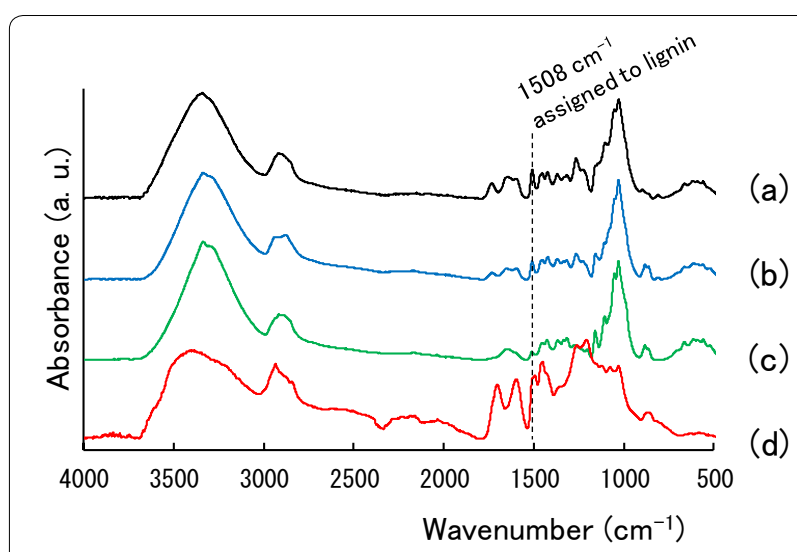

Fig. 2 IR spectra obtained from the radial face of wood block before and after alcoholysis. a-d correspond to Samples 0, 19, 15 and 8 in Table 1, respectively 


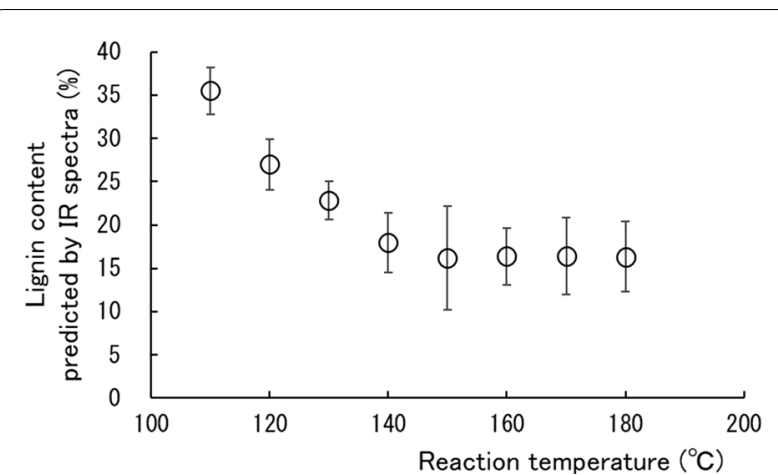

Fig. 3 Lignin content monitored by IR spectroscopy with increasing temperature during alcoholysis. The plots correspond to Samples 11-18 in Table 1. The error bars indicate the standard deviation calculated from 3 samples

exceeding $160{ }^{\circ} \mathrm{C}$. As a result, the solvent mixture in the 99:0.5:0.5 ratio at $150{ }^{\circ} \mathrm{C}$ was determined as the optimum condition for lignin removal and was used throughout this study. The weight of the wood block after alcoholysis under the optimum condition was measured, and yielded $57.6 \%$ that of the original block.

Treatment under high acid concentration as in Sample 8 or high-temperature processing as in Sample No. 21 resulted in increased relative lignin contents. This may have been because these critical treatments preferentially degrade polysaccharides rather than removing lignin. In addition, carbonization was partially carried out, which increased the IR band at $1508 \mathrm{~cm}^{-1}$ ascribed to benzoic skeletal vibration.

\section{Preparation of colorless wood by bleaching}

Figure 4 shows the wood blocks that were subjected to repetitive bleaching treatment. When the bleaching treatment was repeated 4 times, the surface of the wood became colorless, while the core parts remained their color after alcoholysis. On further repetition of bleaching for 8 times, the wood achieved a white coloration, even in the innermost parts. Figure 5 is a control experiment with bleaching treatment 4 times and 8 times without alcoholysis. With increasing bleaching treatment, the wood was decolorized from the surface to the core. However, even after bleaching 8 times, the yellow color was still perceptible in the core, which indicates that alcoholysis was essential for obtaining the colorless block.

Table 2 presents the chemical composition analysis before and after the optimized alcoholysis was performed with or without bleaching for 8 times. After alcoholysis, the amount of lignin that was determined by the weight of solid residue after two-staged acid hydrolyses was decreased to half of the initial content, and hemicellulose
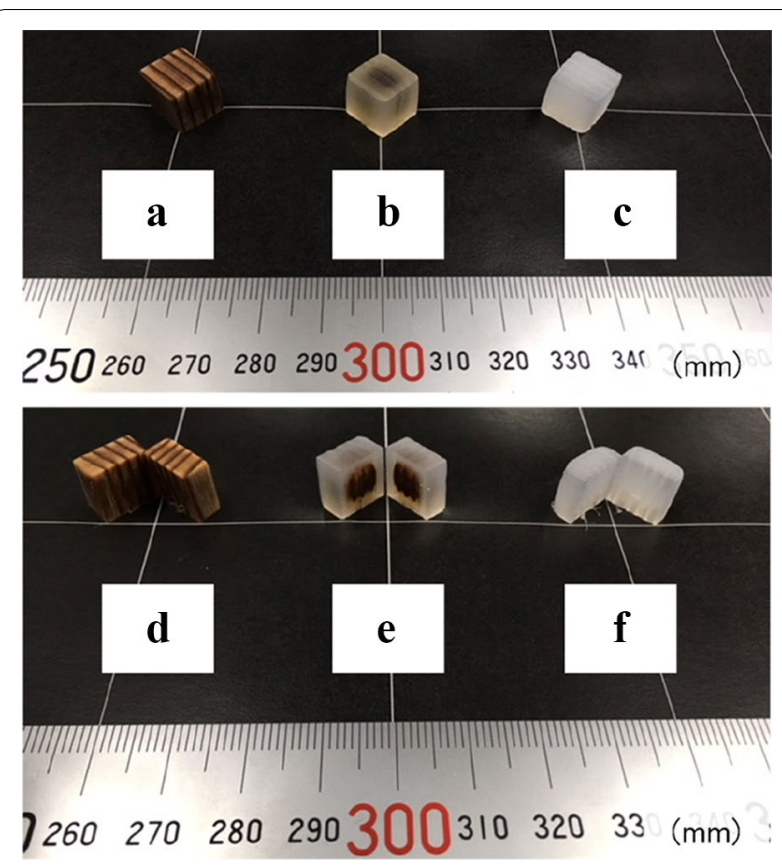

Fig. 4 Wood blocks (a) after alcoholysis, (b) bleaching 4 times and (c) bleaching 8 times. $\mathbf{d}-\mathbf{f}$ The wood blocks corresponding to $(\mathbf{a}-\mathbf{c})$ those were longitudinally cut along the radial direction to observe the inner region

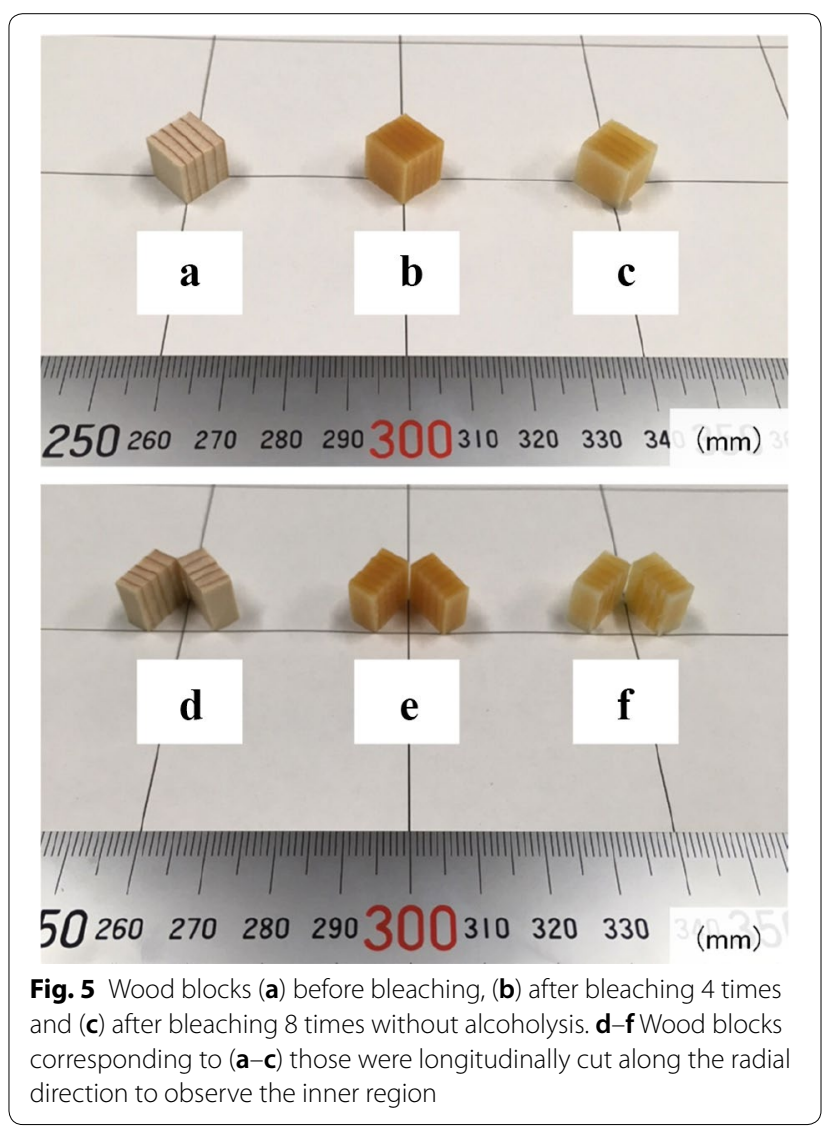


Table 2 Chemical component analysis of the wood before and after 2 step chemical treatment

\begin{tabular}{|c|c|c|c|c|c|c|}
\hline & \multicolumn{6}{|c|}{ Concentration (mg/100 mg) } \\
\hline & Glucan & Xylan & Arabinan & Mannan & Galactan & Lignin \\
\hline Untreated wood & 38.3 & 5.1 & 0.8 & 7.3 & 1.7 & 33.8 \\
\hline After alcoholysis & 65.1 & 1.4 & 0.0 & 1.6 & 0.2 & 13.8 \\
\hline Colorless wood & 86.8 & 1.1 & 0.0 & 0.9 & 0.2 & 0.0 \\
\hline
\end{tabular}

Table 3 Size durability of untreated and colorless wood

\begin{tabular}{|c|c|c|c|c|c|c|}
\hline & \multicolumn{3}{|c|}{ Wet condition (mm) } & \multicolumn{3}{|c|}{ Dry condition $(\mathrm{mm})$} \\
\hline & $L$ & $R$ & $T$ & $L$ & $R$ & $T$ \\
\hline Untreated wood & n. $d$. & n. d. & n. d. & $9.99 \pm 0.05$ & $10.10 \pm 0.02$ & $10.10 \pm 0.18$ \\
\hline Colorless wood & $10.11 \pm 0.05$ & $10.52 \pm 0.18$ & $10.35 \pm 0.08$ & $10.07 \pm 0.08$ & $9.83 \pm 0.28$ & $9.87 \pm 0.07$ \\
\hline
\end{tabular}

The value on size durability shows the average and standard deviation calculated from 3 samples

was also effectively removed, which potentially increased the permeability of the bleaching liquid into the inner cell wall components. After repetitive bleaching, lignin was completely removed from the wood. In addition, xylose and mannose-the main components of hemicellulose in softwood-were less than $2 \%$, which indicated that a combination of optimized alcoholysis and bleaching treatment can form colorless wood that is primarily constructed of cellulose.

\section{Assessment of woody hierarchical structure}

Although the colorless wood was successfully fabricated by the two-step chemical treatment, a confirmation was required regarding its natural hierarchical structure. At first, the dimensional stability was evaluated in wet and dry conditions as shown in Table 3. Under the never-dried conditions, the 3 dimensions were unaltered. When the colorless wood was freeze-dried, the size was unchanged or slightly shorter at the radial and tangential direction. Given the constancy in the $\mathrm{L}$ direction before and after drying, the isotropic contraction seems to have been provided by the anatomical structure involving the tracheid arrangement.

Next, anatomical and cell structures were observed by optical microscopy combined with PAS staining that is sensitive to polysaccharides, especially in hemicellulose in the woody cell wall. The colorless wood mostly consisted of cellulose without hemicellulose, and therefore a incubation was performed of a section from the colorless wood in the Schiff's reagent over a long time to visualize anatomical structure (Fig. 6a, b). Although the staining color was light, the cell arrangement of tracheids, as well as the radial parenchyma cells and resin cells, was maintained. Furthermore, X-ray CT was employed to obtain a

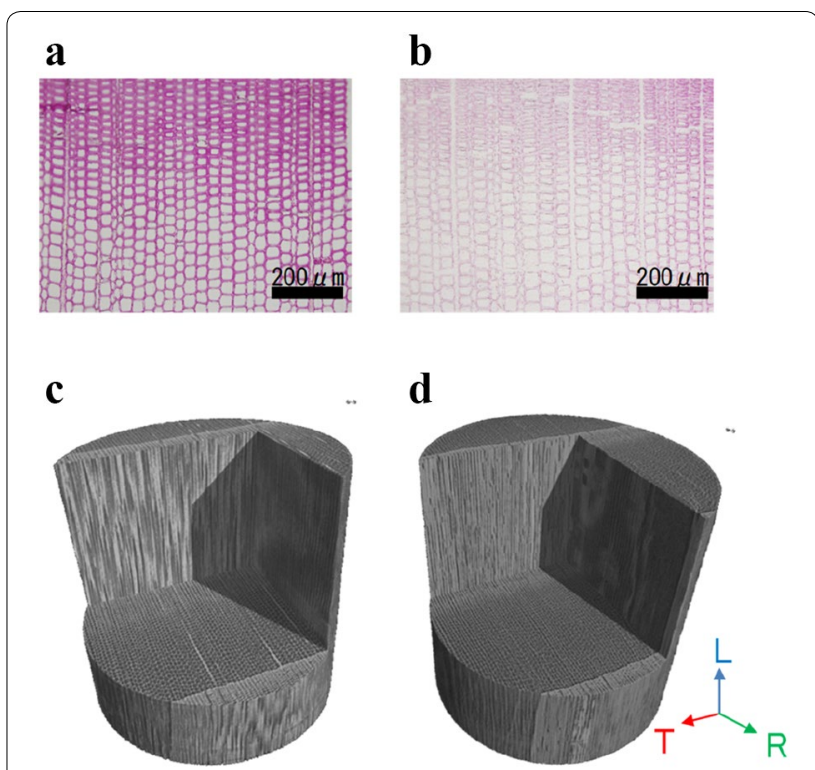

Fig. $\mathbf{6}$ a, b Optical microscopic images after PAS staining, and $\mathbf{c}, \mathbf{d}$ 3-dimensional $\mathrm{X}$-ray $\mu \mathrm{CT}$ images. $\mathbf{a}$, $\mathbf{c}$ are obtained from untreated wood while $\mathbf{b}$ and $\mathbf{d}$ are from the colorless wood, respectively

3-dimensional reconstruction image. Figure $6 c, d$ shows the 3-dimensional structures from the untreated and colorless wood, respectively. In the radial and tangential faces of the colorless wood, the arrangement of the tracheids was clearly visible. In the cross-section, the growth ring could be observed, wherein the arrangement of the cells from earlywood to latewood was preserved.

To investigate whether the microfibril orientation was stored in the cell wall, an X-ray fiber diffractogram was recorded from the radial section, which was rolled along the $\mathrm{L}$-axis to determine the average 


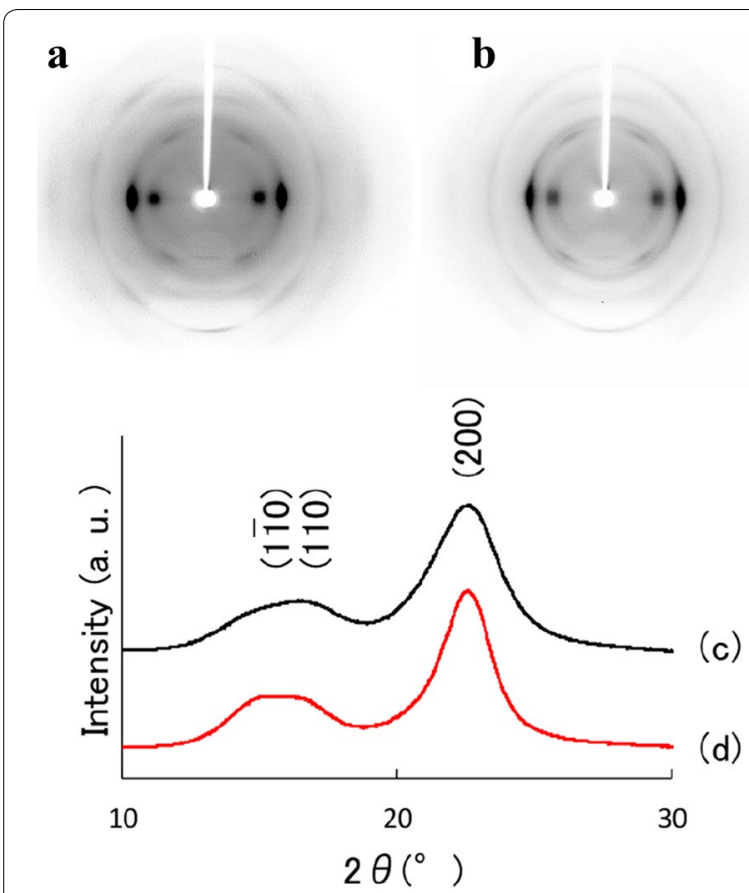

Fig. 7 a, $\mathbf{b}$ X-ray diffraction patterns, and $\mathbf{c}, \mathbf{d}$ X-ray diffractograms. $\mathbf{a}$, $\mathbf{c}$ are obtained from the untreated wood while $\mathbf{b}$ and $\mathbf{d}$ are from the colorless wood, respectively

structural information of earlywood and latewood (Fig. 7). If microfibrils were randomly accumulated in the cell wall, diffraction would follow a multi-circular pattern in a concentric fashion. Similar to the images in Fig. 7a that were obtained from the untreated sample, 2-dimensional diffraction images from the colorless wood present a typical pattern of cellulose fiber diffractogram as shown in Fig. 7b [22]. Microfibril angles were estimated from an X-ray fiber diffractogram by an azimuthal distribution plot that was calculated from (200) reflections, as shown in Table 4. In reference to the published report where the microfibril angle was measured using X-ray diffraction analysis [23, 24], an approximate value of 3 degrees in the untreated wood of $C$. japonica seemed to be small. This may have been because it was ascribed from the $\mathrm{S}_{2}$ layer of latewood involving a relatively smaller microfibril angle. The microfibril angle of colorless wood was similar to that of untreated wood,

Table 4 Microfibril angle, crystalline index and full-width at half-maximum of untreated and colorless wood

\begin{tabular}{llll}
\hline & $\begin{array}{l}\text { Microfibril } \\
\text { angle }(\mathbf{0})\end{array}$ & $\begin{array}{l}\text { Crystallinity } \\
\text { index }\end{array}$ & $\begin{array}{l}\text { Full-width at half- } \\
\text { maximum of (200) } \\
\mathbf{( 0 )}\end{array}$ \\
\hline Untreated wood & 3.22 & 0.56 & 3.18 \\
Colorless wood & 3.54 & 0.63 & 2.50 \\
\hline
\end{tabular}

thus indicating that microfibril orientation in the cell wall was maintained even after the respective processes of alcoholysis and bleaching treatment.

Figure $7 \mathrm{c}, \mathrm{d}$ is the wide-angle $\mathrm{X}$-ray diffractograms in the $10^{\circ}-30^{\circ}$ range. These show similar patterns, which indicate that the colorless wood maintains a natural cellulose crystalline structure. As shown in Table 4, crystalline indices were calculated from the area ratio of the crystal/(crystal + amorphous) by peak separation from $\mathrm{X}$-ray diffractograms. The crystalline index of colorless wood was clearly higher than that of untreated wood. In addition, the full-width at half-maximum at a peak of (200) that can be applied to assess the relative crystallinity was estimated. The value obtained from the colorless wood is smaller than that of the untreated wood, which was consistent with the values of the crystalline index. These analyses suggested that the removal of matrix components improves the orientation of the cellulose microfibril; thereby increasing the relative crystallinity.

Last, in the microstructural stage, morphological assessment of cellulose microfibril was carried out. We utilized the TEMPO-mediated oxidation technique to visualize microfibrils by TEM observation. Figure 8 clearly presents microfibrils whose width is $4.03 \pm 0.68 \mathrm{~nm}$, corresponding to the microfibril width of higher plants. In addition, colorless wood that is chemically treated to remove most of the matrix components had microfibrils with longer fiber lengths. It is well-known that microfibrils generated by terrestrial plants including cotton are easily shortened by acid hydrolysis $[25,26]$. Therefore, the optimized alcoholysis required for the colorless wood was a moderate treatment of its cellulose microfibrils.

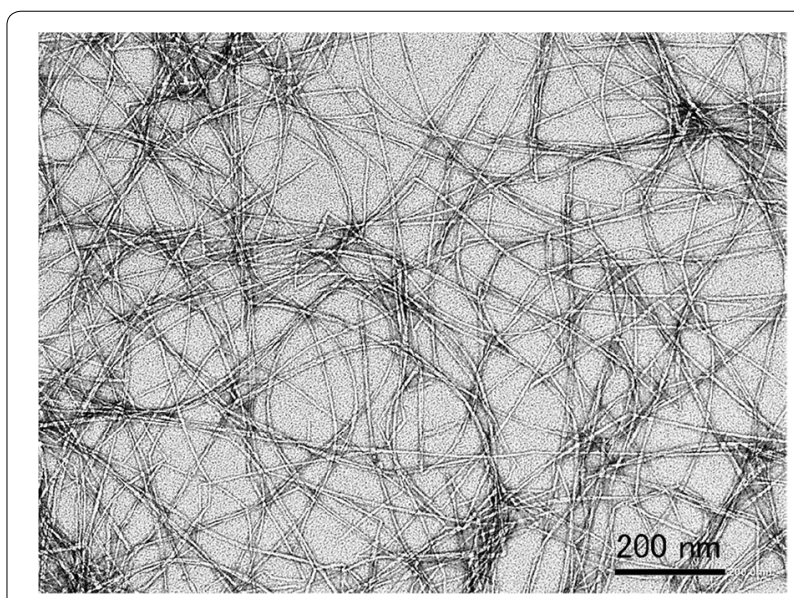

Fig. 8 Transmission electron microscopy image for TEMPO-oxidized cellulose microfibrils prepared from the colorless wood 


\section{Conclusion}

The two-step chemical treatments of alcoholysis coupled with bleaching successfully developed the colorless wood. The block mostly consisted of cellulose, which maintained its inherent architecture from macro- to micro-structure; all stages of its structure were confirmed by multidirectional observation. Lignin-free wood that possesses a natural structure has significant potential as a novel biodegradable material. This is because the functional resin polymer matrix was embedded, thus expressing the novel character that is supported by the woody architecture. In addition, this is a promising specimen that will promote research and investigation on how and why lignin and hemicellulose are organized in the cell wall; consequently, the research study will be directed at investigating mechanical properties such as compression strength depending on lignin deposition combined with the biological diversity of the anatomical structure.

\section{Abbreviations}

TEMPO: 2,2,6,6-tetramethylpiperidine-1-oxyl; $\mu \mathrm{CT}$ : Microcomputed tomography; XRD: X-ray diffraction; TEM: Transmission electron microscopy; IR: Infrared; ATR: Attenuated total reflection; HPLC: High-performance liquid chromatography; PAS: Periodic acid-Schiff.

\section{Acknowledgements}

The authors sincerely appreciate Mr. Adachi of Kyoto University for providing the wood samples. The authors are also grateful to Dr. Kobayashi and Ms. Mihashi of BioJapan Industry for supporting the chemical component analysis. This research study was jointly supported by Grants-in-Aid for Scientific Research (KAKENHI) [Grant Nos. 17K19283 and 19K06167] from the Japan Society for the Promotion of Science (JSPS). This work was also supported by Grants-in-Aid for Sugiyama Chemical \& Industrial Laboratory.

\section{Authors' contributions}

$\mathrm{YH}$ and RT contributed sufficiently to the chemical treatment and hierarchical structural assessment processes. KN contributed to the X-ray diffraction analysis. SN and RF contributed to the anatomical structural analysis. All authors read and approved the final manuscript.

\section{Funding}

This work was supported in part by grants from the Japan Society for the Promotion of Science (KAKENHI, 17K19283 and 19K06167) and Grants from Sugiyama Chemical \& Industrial Laboratory.

\section{Availability of data and materials}

All data and materials in this study are included in this published article.

\section{Competing interests}

The authors declare that they have no competing interests.

\section{Author details \\ ${ }^{1}$ Institute of Agriculture, Tokyo University of Agriculture and Technology, Fuchu, Tokyo 183-8509, Japan. ${ }^{2}$ Institute of Technology, Tokyo University of Agriculture and Technology, Koganei, Tokyo 184-8588, Japan.}

Received: 13 February 2020 Accepted: 8 May 2020

Published online: 19 May 2020

\section{References}

1. Abe K, Iwamoto S, Yano H (2007) Obtaining cellulose nanofibers with a uniform width of $15 \mathrm{~nm}$ from wood. Biomacromology 8:3276-3278

2. Kose R, Mitani I, Kasai W, Kondo T (2011) "Nanocellulose" as a single nanofiber prepared from pellicle secreted by Gluconacetobacter xylinus using aqueous counter collision. Biomacromology 12:716-720

3. Saito T, Kimura S, Nishiyama Y, Isogai A (2007) Cellulose nanofibers prepared by TEMPO-mediated oxidation of native cellulose. Biomacromology 8:2485-2491

4. de Nooy AEJ, Besemer AC, van Bekkum H (1995) Selective oxidation of primary alcohols mediated by nitroxyl radical in aqueous solution. Kinetics and mechanism. Tetrahedron 51:8023-8032

5. Isogai A, Saito T, Fukuzumi H (2011) TEMPO-oxidized cellulose nanofibers. Nanoscale 3:71-85

6. Saito T, Kuramae R, Wohlert J, Berglund LA, Isogai A (2013) An ultrastrong nanofibrillar biomaterial: the strength of single cellulose nanofibrils revealed via sonication-induced fragmentation. Biomacromology $14: 248-253$

7. Iwamoto S, Kai WH, Isogai A, Iwata T (2009) Elastic modulus of single cellulose microfibrils from tunicate measured by atomic force microscopy. Biomacromology 10:2571-2576

8. Noguchi T, Endo M, Niihara K, Jinnai H, Isogai A (2020) Cellulose nanofiber/elastomer composites with high tensile strength, modulus, toughness, and thermal stability prepared by high-shear kneading. Compos Sci Technol. https://doi.org/10.1016/j.compscitech.2020.108005

9. Iwatake A, Nogi M, Yano H (2008) Cellulose nanofiber-reinforced polylactic acid. Compos Sci Technol 188:2103-2106

10. Suzuki K, Sato A, Okumura H, Hashimoto T, Nakagaito AN, Yano H (2014) Novel high-strength, micro fibrillated cellulose-reinforced polypropylene composites using a cationic polymer as compatibilizer. Cellulose 21:507-518

11. Yano H, Hirose A, Collins PJ, Yazaki Y (2001) Effects of the removal of matrix substances as a pretreatment in the production of high strength resin impregnated wood based materials. J Mater Sci Lett 20:1125-1126

12. Li YY, Fu QL, Yu S, Yan M, Berglund L (2016) Optically transparent wood from a nanoporous cellulosic template: combining functional and structural performance. Biomacromology 17:1358-1364

13. Song JW, Chen CJ, Zhu SZ, Zhu MW, Dai JQ, Ray U, Li YJ, Kuang YD, Li YF, Quispe N, Yao YG, Gong A, Leiste UH, Bruck HA, Zhu JY, Vellore A, Li H, Minus ML, Jia Z, Martini A, Li T, Hu LB (2018) Processing bulk natural wood into a high-performance structural material. Nature 554:224-228

14. Hallac BB, Sannigrahi P, Pu YQ, Ray M, Murphy RJ, Ragauskas AJ (2010) Effect of ethanol organosolv pretreatment on enzymatic hydrolysis of Buddleja davidii stem biomass. Ind Eng Chem Res 49:1467-1472

15. Jimenez L, Rodriguez A, Diaz MJ, Lopez F, Ariza J (2004) Organosolv pulping of olive tree trimmings by use of ethylene glycol/soda/water mixtures. Holzforschung 58:122-128

16. Demirbas A (1998) Aqueous glycerol delignification of wood chips and ground wood. Bioresour Technol 63:179-185

17. Pan XJ, Arato C, Gilkes N, Gregg D, Mabee W, Pye K, Xiao ZZ, Zhang X, Saddler J (2005) Biorefining of softwoods using ethanol organosolv pulping: preliminary evaluation of process streams for manufacture of fuel-grade ethanol and co-products. Biotechnol Bioeng 90:473-481

18. Wise L, Murphy M, D'Addieco A (1946) Chlorite holocellulose, its fractionation and beating on summative wood analysis and studies on the hemicelluloses. Pap Trade J 122:35-43

19. Horikawa Y, Imai T, Takada R, Watanabe T, Takabe K, Kobayashi Y, Sugiyama $J$ (2011) Near-infrared chemometric approach to exhaustive analysis of rice straw pretreated for bioethanol conversion. Appl Biochem Biotech 164:194-203

20. Rabemanolontsoa H, Saka S (2013) Comparative study on chemical composition of various biomass species. Rsc Adv 3:3946-3956

21. Takaichi S, Saito T, Tanaka R, Isogai A (2014) Improvement of nanodispersibility of oven-dried TEMPO-oxidized celluloses in water. Cellulose 21:4093-4103

22. Horikawa Y, Hirano S, Mihashi A, Kobayashi Y, Zhai SC, Sugiyama J (2019) Prediction of lignin contents from infrared spectroscopy: chemical digestion and lignin/biomass ratios of Cryptomeria japonica. Appl Biochem Biotech 188:1066-1076

23. Donaldson L (2008) Microfibril angle: measurement, variation and relationships - a review. IAWA J 29:345-386 
24. Yamamoto H, Okuyama T, Yashida M (1993) Method of determining the mean microfibril angle of wood over a wide range by the improved Caves method. Mokuzai Gakkaishi 39:118-125

25. Barnett JR, Bonham VA (2004) Cellulose microfibril angle in the cell wall of wood fibres. Biol Rev 79:461-472

26. Nickerson RF (1947) Cellulose intercrystalline structure. Ind Eng Chem 39:1507-1512

27. Horikawa Y, Shimizu M, Saito T, Isogai A, Imai T, Sugiyama J (2018) Influence of drying of chara cellulose on length/length distribution of microfibrils after acid hydrolysis. Int J Biol Macromol 109:569-575

\section{Publisher's Note}

Springer Nature remains neutral with regard to jurisdictional claims in published maps and institutional affiliations.

\section{Submit your manuscript to a SpringerOpen ${ }^{\odot}$ journal and benefit from:}

- Convenient online submission

- Rigorous peer review

- Open access: articles freely available online

- High visibility within the field

- Retaining the copyright to your article

Submit your next manuscript at $\boldsymbol{\nabla}$ springeropen.com 